\title{
Epidemiological and Clinical Predictors of License for Health Care Due to MBD
}

\author{
Davi Baasch* (D, Roberto Moraes Cruz (Đ, \& Rafaela Luiza Trevisan (® \\ Universidade Federal de Santa Catarina, Florianópolis, SC, Brasil
}

\begin{abstract}
This article aimed to check the association between clinical and epidemiological predictors of sick leave due to mental and behavioral disorders in public servants. Two databases were used: one epidemiological, with demographic and occupational data of public servants from Santa Catarina, enabling prevalence calculations for this population; one clinical, with results from three instruments in a representative sample of 822 servants. The prevalence of epidemiological variables from each sample servant has been associated with their clinical scores (obtained by the instruments), allowing comparisons between clinical and epidemiological predictions. As a result, it was found that regression models covering both clinical and epidemiological variables have explained larger parts of the outcomes' range (reaching $60.7 \%$ of benefits granted). It is concluded, finally, that although psychology and epidemiology are distinct sciences, their remarkable contributions to health complement each other. Such articulation is rare in literature and enhances the psychological tradition of clinical studies. Therefore, it enriches the field in order to promote and protect mental health, as well as to prevent mental disorders, in work environments.
\end{abstract}

KEYWORDS: mental disorders, prevalence, mental health, regression analysis, psychometrics

\section{Preditores Epidemiológicos e Clínicos de Afastamentos porTMC em Servidores Públicos}

\begin{abstract}
RESUMO - O objetivo do artigo foi verificar a associação entre preditores clínicos e epidemiológicos de afastamento do trabalho por transtorno mental em servidores públicos. Duas bases de dados foram utilizadas: uma epidemiológica, com dados demográficos e ocupacionais dos servidores do Estado de Santa Catarina, possibilitando cálculos de prevalência nessa população; outra clínica, com resultados de três instrumentos numa amostra representativa de 822 servidores. As prevalências das variáveis epidemiológicas de cada servidor da amostra foram associadas aos seus respectivos escores de instrumentos clínicos, permitindo comparações entre predições clínicas e epidemiológicas. Como resultado, observou-se que modelos de regressão envolvendo dados clínicos e epidemiológicos ao mesmo tempo explicam parcelas maiores da variância dos benefícios concedidos (chegando a 60,7\%). Por fim, conclui-se que, apesar de psicologia e epidemiologia serem ciências distintas, suas notáveis contribuições para a saúde complementam-se. Tal articulação é raramente vista na literatura nacional e internacional e extrapola a tradição psicológica de estudos clínicos, enriquecendo-a no intuito de fomentar a promoção e proteção à saúde mental, assim como a prevenção contra transtornos mentais, em ambientes de trabalho.
\end{abstract}

PALAVRAS-CHAVE: transtornos mentais, prevalência, saúde mental, análise de regressão, psicometria

Mental and Behavioral Disorders (MBD) are significant changes in the individual's cognition, emotional regulation, or behavior that lead to dysfunction in psychological, biological, or developmental processes supported by mental functioning; these are commonly associated with substantial suffering or inability, which affect his social, professional, or other relevant activities (American Psychiatry Association,
2013). MBD are morbidities that affect a significant part of workers in Brazil and worldwide, with different backgrounds.

Regarding the mental health of civil servants, there are, at least, two approaches to understand this phenomenon that coexist: one centered on the characteristics of individuals (clinical), and the other centered on population or contextual

*E-mail: davibaasch@gmail.com

- Submetido: 14/06/2017; Revisado: 09/04/2019; Aceito: 20/04/2020. 
characteristics (epidemiology). Hence, we defined the following question: to what extent are the predictions on sick leave due to MBD strong, when considering, at the same time, clinical and contextual attributes of the servant?

This article aims to check the association between clinical and epidemiological predictors of sick leave due to mental and behavioral disorders (MBD), in public servants of the State of Santa Catarina (SC). To this end, we developed three hypotheses: (1) measures of mental suffering, anxiety, and depression are positively related to sick leave by MBD, and to its duration; (2) resilience measures are negatively associated with sick leave by MBD, and to its duration; (3) regression models that use only clinical or epidemiological data have much lower predictive capacity than models that use both data simultaneously (that is, both are complementary).

Epidemiology is a science that studies the distribution of health/disease phenomena quantitatively, and their conditioning and determining factors in human populations, in order to provide subsidies for disease prevention (Carvalho et al., 2017). It is evident that the analysis of causal determination of diseases in a human community, divided in social classes or specific groups of populations, requires an interdisciplinary approach of epidemiology, and depends on other sciences, such as psychology.

Psychometric studies related to clinical psychology measure variables related to mental and behavioral disorders. In order to do that, they require from psychological phenomena a relationship with numbers (Pasquali, 2017) - the same way that epidemiology assigns numbers to the description of population phenomena of health/disease. If, on the one hand, psychometrics allows measuring some characteristics and predicting the occurrence of mental health problems, on the other hand, epidemiology registers their occurrence, seeking possibilities for prevention. It seems that epidemiology and psychometrics are complementary, regarding mental health (Czeresnia, 2008; Palinkas \& Hoiberg, 1982; Vinck et al., 2004), but epistemologically, there is yet no bridge between the two areas, and empirically, literature has not shown evidence of cooperation between psychology and epidemiology.

The object of study is the public servant's mental health. Considered a right of all workers and a State's duty, worker's health in Brazil has a theoretical-methodological approach in the field of collective health, and seeks to understand the health-disease process of human groups in their relationship with labor, in order to design intervention strategies (Gomez et al., 2018; Osmo \& Schraiber, 2015). For the worker's health, the explanation of health problems goes beyond the factors present at the workplace, and adds the cultural, political, and economic meaning that society assigns to them. Biological phenomena are seen through their social dimension, which regards the worker's body in its relationships with nature, in its ability to create and recreate itself through work (Codo, 1999).
Psychological examination is one of psychological assessment modalities for answering specific demands, supporting decisions, and demonstrating evidence. Therefore, the psychologist's performance as an expert has particularities directly related to the context where the professional works (CFP Resolution No. 17, 2012; Cruz, 2017, 2020). The evaluation can be judicial or extrajudicial, and is usually done by specialists, who carry out a detailed work (Silva et al., 2014). Extrajudicial psychological assessment differs from the judicial because it does not relate to the forensic context and to a judge's determination, but falls within the administrative scope. In Brazil, this type of psychological assessment is a common procedure in instances of healthcare official administrative examination (Cruz, 2017). The psychologist works in the field of occupational health, and this type of psychological assessment must consider, in a critical and detailed way, the organization of work and the conditions for its achievement. Thus, he/she must understand the subjective impacts of the situations experienced at the workplace, which can relate to the health of those examined (Araújo \& Barros, 2019; Faiman, 2012; Lacaz, 2016).

At the public service, official health examination is, above all, an administrative, mandatory, and investigative activity, called Administrative Evaluation or Official Health Evaluation (Ministério do Planejamento, Orçamento, e Gestão, 2010). It is a technical assessment of issues related to health and work capacity, carried out in the servant's presence, by a multidisciplinary team, according to the concept of biopsychosocial health. It is up to the expert to examine the employee for establishing a link between the observed limitation and the ability to work (Carneiro, 2006). The expert must act as an administrative authority, to grant the benefits provided by law (Decree no. 3388/2010; Bim \& Murofuse, 2014), many of which refer to mental and behavioral disorders (MBD) (Almeida et al., in press).

MBD are among the diseases that most affect workers in Brazil and worldwide, and are understood as psychological patterns that harm workers seriously and cause losses at the workplace. Epidemiological surveillance in mental health has shown that their prevalence are a little above $20 \%$, reaching, in some cases, much higher percentages - as in civil servants in the Stare of SC (above 35\%) (Secretaria de Estado da Administração de Santa Catarina, 2015, 2018a, 2018b; Baasch et al., 2017).

Specific literature confirms that MBD affect a significant part (often above $30 \%$ ) of public servants throughout their careers (Alarcon \& Guimarães, 2016; Baasch et al., 2017; Leão et al., 2015; Secretaria de Estado da Administração de Santa Catarina, 2015, 2018a, 2018b; Silva et al., 2012). Public administration professionals have a wide variety of functions and social relevance. At the same time, such workers are exposed to different requirements that often result from the bureaucratic management model, typical of public organizations, such as increased workload, limitations 
arising from the existing normative rigidity, decreased autonomy, new temporary/outsourced contracts, etc.
Therefore, this research is justified not only by its scientific relevance, but also social.

\section{METHOD}

We used the association of indicators from two very different designs: epidemiological and clinical. The first involved the survey of the epidemiological profile of cases of benefits granted by MBD among civil servants in the State of SC. We defined the prevalence of MBD in each available demographic and occupational variable (1. working agency; 2. income ranges, 3. gender, 4. age ranges, 5. ethnicity, 6 . marital status, 7. level of education, 8. ranges of service time, 9. server's position/function, and 10. city of SC State). We later used the prevalence of these 10 variables as epidemiological predictors in regression analysis.

For the clinical/psychometric design we used a research protocol composed of three clinical instruments (of self-report), designed to assess (1) resilience, (2) mental suffering, and (3) anxiety and depression. We made this protocol available in two ways: (1) through the government Medical Examination Management, in which employees answered it minutes before having their health condition assessed; and (2) electronically, through the website www. portaldoservidor.sc.gov.br, the electronic address most accessed by servers (where the government disseminates different services, information, and news relevant to them). Each answered instrument generated a score, later used as a (clinical) predictor in regression analysis. Therefore, we could combine epidemiological and clinical predictors in the same database.

\section{Participants}

We used three servants' databases: (1) one with data from all civil servants in the State of SC (effective and active), who were on Doctor-Certified Sick Leave (SL) by MBD (code F of CID-10); (2) another with data from the total population (effective and active servants, on sick leave or not), necessary for prevalence calculations; and (3) a third with clinical data from a representative sample of 822 servants (effective and active) that answered the research protocol (three instruments). This database had 480 responses from servers without records of benefits by MBD (between 2010 and 2015), and 342 responses from servers with benefits by current or previous MBD (benefits of removal, rehabilitation, or SL by MBD between 2010 and 2015). This group had 219 who received some benefit by MBD at the time they completed the research protocol, and 123 who did not have such benefits at that time, but had them in the past.

Within the sample of servants, 269 answered the research protocol on paper, during state examinations (before their condition was assessed), and 553 answered it electronically. The scores achieved by the examined individuals indicated that they presumably had MBD, while the others were assumed healthy (without MBD). This allowed conducting internal validity analysis through intergroup correlation. Table 1 outlines the number of servants in each situation (without MBD history, with previous MBD history, and with MBD at the time of examination), as well as the flow of the sample data collection.

Some participants answered the protocol twice: once on paper (at the examination), and another later, by the Internet. We excluded these repeated cases from the database, always keeping the first answer (the protocols had a date).

In order to estimate the representation of the sample in relation to the total population of civil servants in the State of SC, Table 2 compares frequencies of categorical variables in the sample $(\mathrm{N}=822)$ with those in the total population $(\mathrm{N}=45,599)$. In addition, means, standard deviations, and medians of sample continuous variables $(\mathrm{N}=822)$ and of the population $(\mathrm{N}=45,599)$ were similar. These values were: Age (Xsample $=47.02$ years old; SDsample $=7.79$ and Xpopulation $=45.47$; SDpop. $=9.63$ ), Service Time $($ Xsample $=16.07$ years; SDsample $=7.86$ and Xpop. $=$ 14.88; SDpop. $=10.21)$, Wage $($ Xsample $=\mathrm{R} \$ 5,274.19$; SDsample $=\mathrm{R} \$ 3,335.43$ and Xpop. $=\mathrm{R} \$ 5,859.67$; SDpop. $=\mathrm{R} \$ 5,163.25)$.

Despite the non-randomness of the sample, comparisons between sample and total population variables show significant similarities, both in means and standard deviations of the scalar variables, and in frequencies of the categorical variables, thus ensuring sample representation.

Finally, the clinical-epidemiological database added the prevalence that corresponded to demographic and occupational variables for each sample participant. That

Table 1

Data collection locations

\begin{tabular}{lcccc}
\hline Data collection location & Without MBD & Previous MBD & Current MBD & Total \\
\hline State examination units & 27 & 26 & 216 & 269 \\
Servants' Web Portal & 453 & 97 & 3 & 553 \\
Total & 480 & 123 & 219 & 822 \\
\hline
\end{tabular}


Comparisons between Frequencies of Categorical Variables in Sample and in Total Population

\begin{tabular}{|c|c|c|c|c|}
\hline & Sample & $\%$ & Pop. & $\%$ \\
\hline \multicolumn{5}{|l|}{ Gender } \\
\hline Men & 176 & 21.5 & 16383 & 35.9 \\
\hline Women & 644 & 78.5 & 29216 & 64.1 \\
\hline \multicolumn{5}{|l|}{ Ethnicity } \\
\hline Asian & 2 & 0.2 & 120 & 0.3 \\
\hline Caucasian & 750 & 91.2 & 42136 & 92.4 \\
\hline Native (indigenous) & 0 & 0.0 & 118 & 0.3 \\
\hline African descend. & 16 & 1.9 & 1282 & 2.8 \\
\hline Brown & 25 & 3.0 & 1123 & 2.5 \\
\hline Absent & 29 & 3.5 & 820 & 1.8 \\
\hline \multicolumn{5}{|l|}{ Education } \\
\hline Basic education & 7 & 0.9 & 2443 & 5.4 \\
\hline High school & 146 & 17.8 & 9600 & 21.1 \\
\hline Higher education & 201 & 24.5 & 9646 & 21.2 \\
\hline Graduate school & 438 & 53.3 & 22499 & 49.3 \\
\hline Absent & 30 & 3.6 & 1410 & 3.1 \\
\hline \multicolumn{5}{|l|}{ Marital Status } \\
\hline Single & 253 & 30.8 & 12257 & 26.9 \\
\hline Married/Partnership & 450 & 54.7 & 27695 & 60.7 \\
\hline Widower & 12 & 1.5 & 772 & 1.7 \\
\hline Separated/Divorc. & 88 & 10.7 & 4812 & 10.6 \\
\hline Absent & 19 & 2.3 & 63 & 0.1 \\
\hline
\end{tabular}

is, each of the 822 servers in the sample had a number corresponding to the prevalence (value between 0 and $100 \%$ ) of each of the (10) variables used. Therefore, we inserted 8,220 new data pieces into the bank.

\section{Instruments}

We used the Brief Resilience Scale - BRS (Smith et al., 2008) for measuring resilience. It is a short instrument, of quick application, composed by six items arranged on a five-point Likert scale, which assumes resilience as "getting rid of stress". BRS showed significant internal consistency and construct validity (results confirmed several specific hypotheses). The result of those authors' exploratory research still found that the factor "getting rid of stress" (single) was negatively associated with healthrelated outcomes (anxiety and depression), and positively associated with the presence of resilience resources, such as types of confrontation and social support. Nevertheless, this instrument showed convergent results with resilience scales already established in international literature Connor-Davidson Resilience Scale or CD-RISC, Ego Resiliency. Compared to other resilience scales presented in the literature review, BRS shows some advantages: 1) it is a measure of resilience, not of 'protective resources that foster resilience', such as the Resilience Scale for Adults (Friborg et al., 2005), or of 'psychological resistance', such as the Dispositional Resilience Scale - which also showed less evidence of validity and accuracy (Bartone et al., 2008); 2) it is of fast application, comprising only six items - instead of 25 as the CD-RISC and the Resilience Scale, or 31 as the Essential Resilience Scale; 3) it is directed toward adults, and not teenagers, as the Brazilian version of the Resilience Scale (Pesce et al., 2005); and 4) it is quite recent, published in 2008.

In order to measure mental suffering, we used the SelfReporting Questionnaire (SRQ-20). Since it is a tracking instrument, not used for diagnosis, the definition of the cutoff point of SRQ-20 for case determination must be compared with the gold standard. In Brazil, in the mid-1980s, Mari and Williams (1986) translated and validated SRQ-20. The results were compared with the formal psychiatric interview (gold standard), by using the semi-structured instrument CIS (Clinical Interview Schedule for DSM-IV). The achieved sensitivity was $83 \%$ and the specificity was $80 \%$, proving to be a good indicator of morbidity (Gonçalves et al., 2008; Mari \& Williams, 1986). Used in several countries (Husain et al., 2016; Netsereab et al., 2018; Paraventi et al., 2015; Van Der Westhuizen et al., 2018), the 20 questions that make up the questionnaire have two alternative answers (yes or 
no), and were designed to address emotional and physical symptoms associated with psychiatric conditions. The cutoff point for classifying as MBD is above seven positive responses (that is, results between 8 and 20) (Gonçalves et al., 2008; Tuan et al., 2004).

The Hospital Anxiety and Depression Scale, also known as the HAD Scale - or simply HADS (Annex C) - was used in order to measure anxiety and depression among the participants. It is a self-report scale with 14 multiplechoice questions. It consists of two subscales (HADS-A and HADS-D), for anxiety and depression, with seven items each. Participants should answer based on how they felt during the previous week. The global score in each subscale ranges from zero to 21, and has a cut-off point of eight for anxiety and nine for depression (Faro, 2015; Macêdo et al., 2017).

The concepts of depression and anxiety are two factors of HADS, related to the subscales HADS-A and HADS-D (Faro, 2015; Macêdo et al., 2017; Mykletun et al., 2001). HAD scale aims to detect mild degrees of affective disorders in non-psychiatric hospital settings. As advantages, it is a short measure that is quickly completed, and has proved to be a highly sensitive instrument for the detection of anxiety and depression (Faro, 2015; Macêdo et al., 2017). The measure has appropriate internal consistency, inter-correlation, homogeneity, and good performance in assessing the severity of symptoms of anxiety and depression disorders (factor structure) in psychiatric, somatic, and primary care patients, as well as in the general population (Bjelland et al., 2002; Mykletun et al., 2001).

\section{Procedures}

Regarding the database with information on effective and active civil servants of State of SC that were on sick leave by MBD, we defined the period between January 2010 and December 2014. It included 13 variables, nine independent, and four dependent. Demographic variables (independent) were: (1) gender, (2) age, (3) race, (4) marital status, and (5) education level of the licensed employee. Occupational variables (independent) were: (6) position, (7) workplace (government body), (8) city of work, and (9) service time (in years). And outcome variables (dependent): (1) initial year of leave, (2) amount paid, (3) number of days granted, and (4) CID-10 code assigned to the main reason for the leave (SL). The 'income' variable (paid value) was also used as an independent variable. The assumption was that higher incomes allow servants to have more resources for preventing MBD or for care and rehabilitation of their mental health (Sareen et al., 2011).
The database with information of all effective and active civil servants of the State of SC had seven variables: (1) year of observation (we chose the month of October as standard, by showing less variation among the years), (2) server's identification number, (3) workplace (government body), (4) race, (5) education level, (6) position, and (7) city of work. We excluded any repeated identification numbers, since some employees had more than one employment link with the State of SC. We kept the numbers that appeared in the bank for the first time (random criterion).

\section{Data Analysis}

We used the accumulated prevalence: servants in SL (2010-2014) / total of servants x 100 (percentage). In order to test predictors of mental health at work, we used:

1. Linear regression analysis, using as predictors the instrument scores (clinical variables) and the prevalence of demographic and occupational variables of the participating employees. As dependent variables of these linear regressions, we used the scalar variables of the outcomes, namely: leave period (in days), number of SL received (by MBD) since Jan/2010, and total accumulated time (in days) of SL since Jan/2010.

2. Logistic regression analysis, using as predictors the instrument scores (clinical variables) and the prevalence of demographic and occupational variables of the participating servants (epidemiological variables). As dependent variables of these logistic regressions, we used the benefits resulting from MBD. We divided servants in two groups: those that enjoyed some benefit by MBD, and those with no previous MBD record (since Jan/2010). We did not consider servants who did not receive any benefit but had a record of previous leave, in order to reduce the spurious variance in the models.

\section{Ethical Considerations}

We observed all ethical principles regarding the development of this research (Resolution CNS n. 466/2012). It was authorized by the State Secretariat of Management of Santa Catarina, and approved by the Committee on Research Ethics of the Secretariat of Health of the State of SC (CEPSES-SC), under the n. CAAE 36112214.5.0000.0115. 


\section{RESULTS}

Pearson's correlations resulting from the association between the prevalence of demographic-occupational variables of each servant in the sample, and the scores of the instruments answered by them, were significant and as expected: mental suffering, anxiety, and depression positively associated with each other, and resilience negatively associated with sick leaves by MBD and their duration. However, such correlations were generally weak.

The highest correlations found were between the instruments' scores and the prevalence of servants' income ranges, with values around 0.2 (and $p$-value always $<0.05$ ) - the highest significant correlation found between scores and prevalence was between the SRQ-20 (mental suffering) score and the prevalence of servants' income ranges $(0.249$ and $p$-value $<0.01)$. The lowest significant correlation found was between the HADS-D score (depression) and the prevalence of the server's education level ( 0.071 and $p$ $<0.05$ ). Correlations between BRS (resilience) scores and MBD prevalence were always negative, and correlations between HADS and SRQ-20 scores were always positive, as expected. The significant correlations found ranged from 0.071 to 0.249 , but typically were around 0.1 .

From these results, we tested the complementarity hypothesis. It assumes that clinical information explains part of the outcome variance (benefits by MBD in servants), while epidemiological information explains another part of this same variance. Since higher correlations suggest more explanatory capacity for these two sets of variables, we carried out regression analyses in order to test this hypothesis.
Table 3 shows the adjusted $\mathrm{R}^{2}$ coefficients of determination of linear regressions, involving scores of the instruments used and prevalence of demographic and occupational variables of the employees in the sample, such as predictors of time of sick leave (SL) by MBD. We excluded servants not currently on leave, but with a record of benefits by previous CID-F (from Jan/2010 until response to the research protocol), since these carried a spurious variance in both groups. In other words, they do not belong to the "presumably healthy" group, because they were recently on leave. In addition, they do not belong to the group with MBD, since they currently are not on sick leave. Therefore, there were 480 servants without SL by MBD and no history of SL, and 119 servants who got SL by MBD when they answered the instruments.

In Table 3, we observe that the explained variance of 'duration of sick leave' increases significantly, since psychometric/clinical data are linked to epidemiological data. From these data, if an expert, hypothetically, depended only on information on MBD prevalence among those examined, for granting SL, he would have a much higher chance of making a mistake, compared to another expert who, in addition to prevalence (of demographic and occupational variables), also counted on clinical results, by using the research protocol (HADS, SRQ-20, and BRS). If an expert uses exclusively the four clinical scores of this research, for example, he will be able to predict only $21.7 \%$ of the time variance granted to SL by MBD. On the contrary, if he adds the prevalence of the variables used in

Table 3

Adjusted $R^{2}$ Determination Coefficients of Linear Regressions Involving Instruments' Scores and Prevalence (Predictors), and Time of SL by MBD Enjoyed by the Servant at the Time of Collection

\begin{tabular}{lc}
\hline Predictors & Time away (SL by MBD) \\
\hline $\mathrm{N}$ & 599 \\
HADS (A + D) + SRQ-20 + BRS & $.217^{* *}$ \\
Prev. Agency & $.029^{* *}$ \\
Prev. Income Ranges & $.010^{*}$ \\
Prev. Gender & -.001 \\
Prev. Age Ranges & $.012^{* *}$ \\
Prev. Ethnicity & -.002 \\
Prev. Marital Status & $.006^{*}$ \\
Prev. Education & $.010^{* *}$ \\
Prev. Ranges of Service Time & $.011^{* *}$ \\
Prev. Function/Position & $.008^{*}$ \\
Prev. City & $.010^{* *}$ \\
All prevalences & $.117^{* *}$ \\
All significant prevalences & $.119^{* *}$ \\
HADS (A + D) + SRQ-20 + BRS + All significant prevalences & $.315^{* *}$ \\
\hline
\end{tabular}

Note. $* \mathrm{~F}$ tests (ANOVA) with p-value $<0.05 ; * * \mathrm{~F}$ tests (ANOVA) with $\mathrm{p}$-value $<0.01$. 
this research as predictors, he will increase his predictive capacity from $21.7 \%$ to $31.5 \%$.

Table 4 shows the adjusted $\mathrm{R}^{2}$ coefficients of determination of linear regressions involving scores of the instruments used, and prevalence of demographic and occupational variables of the servants in the sample, as predictors of: (1) amount of SL by MBD received by the servants, and (2) total time in SL by MBD since Jan 2010. We included all servers in the sample $(\mathrm{N}=822)$, of which 480 had no record of benefit by CID-F (MBD), and 342 had some record of that benefit.
Table 4 refers to the background of the participating servants. Hence, it shows lower values than Table 3. It is reasonable to deduce that the used demographic, occupational, and clinical variables (instruments' scores) have more influence on current than on past MBD. Yet, it is interesting to observe the trend of determination coefficients increase, whenever clinical and epidemiological data are included in the same regression model.

Table 5 presents summarized results of binary logistic regressions involving the instruments' scores and prevalence of demographic and occupational variables as predictors of

Table 4

Adjusted $R^{2}$ Determination Coefficients of Linear Regressions Involving Instruments' Scores and Prevalence (Predictors), and Servants' Outcome Variables - Amount of SL and Total Time in SL since Jan/2010

\begin{tabular}{lcc}
\hline Predictors & N SL from 2010 on & Total time in SL from 2010 on \\
\hline HADS (A+ D) + SRQ-20 + BRS & $.130^{* *}$ & $.104^{* *}$ \\
Prev. Agency & $.060^{* *}$ & $.048^{* *}$ \\
Prev. Income Ranges & $.014^{* *}$ & $.007^{* *}$ \\
Prev. Gender & -.001 & -.001 \\
Prev. Age Ranges & $.029^{* *}$ & $.018^{* *}$ \\
Prev. Ethnicity & -.001 & -.001 \\
Prev. Marital Status & $.005^{*}$ & -.001 \\
Prev. Education & .002 & .000 \\
Prev. Ranges of Service Time & $.009^{* *}$ & $.007^{* *}$ \\
Prev. Function/Position & $.019^{* *}$ & $.011^{* *}$ \\
Prev. City & $.020^{* *}$ & $.016^{* *}$ \\
All prevalences & $.113^{* *}$ & $.074^{* *}$ \\
All significant prevalences & $.099^{* *}$ & $.072^{* *}$ \\
HADS (A + D) + SRQ-20 + BRS + All & $.183^{* *}$ & $.144^{* *}$ \\
significant prev. & & \\
\hline
\end{tabular}

Note. $\mathrm{F}$ tests (ANOVA) with p-value $<0.05 ;{ }^{* *} \mathrm{~F}$ tests (ANOVA) with $\mathrm{p}$-value $<0.01$. N=822.

Table 5

Nagelkerke's $R^{2}$ Coefficient (Logistic Regression) - Benefit Granted To Servant By MBD, As Dependent Variable

\begin{tabular}{lc}
\hline Predictors & $\mathbf{R}^{\mathbf{2}}$ Nagelkerke \\
\hline HADS (A + D) + SRQ-20 + BRS & $.379^{* *}$ \\
Prev. Agency & $.250^{* *}$ \\
Prev. Income Ranges & $.041^{* *}$ \\
Prev. Gender & .001 \\
Prev. Age Ranges & $.064^{* *}$ \\
Prev. Ethnicity & .000 \\
Prev. Marital Status & .025 \\
Prev. Education & .000 \\
Prev. Ranges of Service Time & .049 \\
Prev. Function/Position & $.043^{* *}$ \\
Prev. City & $.045^{* *}$ \\
All significant prevalences & $.378^{* *}$ \\
HADS (A + D) + SRQ-20 + BRS + All significant prevalences & $.607^{* *}$ \\
\hline
\end{tabular}

Note. all ** values showed coefficient tests of the Omnibus model and variables in equations with p-value $<0.01$. $\mathrm{N}=699$. 
benefits granted by MBD. Servants without benefits from CID-F, but with some benefit record from previous MBD (since Jan/2010; $\mathrm{N}=123$ ) were excluded from the models, to reduce their spurious variance (as explained in Table 3 ).

Table 5 reveals, maybe, the most surprising result of this research: the variance in granting benefits by MBD explained by the scores of clinical instruments (37.9\%) is practically equal to the variance explained by the significant prevalences used (37.8\%). However, when placed in the same model, the explained variance increases significantly. Clinical and epidemiological data explained over $60 \%$ of the benefits granted by MBD to servants in the sample. In other words, even without requiring expert work and detailed evaluations, we predicted over half of the benefits granted by CID-F. It is a very relevant expert subsidy, especially when considering that it is a cross-sectional research.

\section{DISCUSSION}

Although simple and brief, the study showed that the three self-report instruments used, especially HADS and SRQ-20, have appropriate psychometric properties (Bjelland et al., 2002; Faro, 2015; Gonçalves et al., 2008; Macêdo et al., 2017; Mari \& Williams, 1986; Mykletun et al., 2001), and provided a significant contribution to the results of the regression analysis. However, clinical predictions of work leaves of public servants in Santa Catarina by MBD are associated with epidemiological predictions, because all regression models (Tables 3, 4 and 5) explained larger parts of the outcomes' variance. This happened because they added demographic and occupational variables of the population, which characterized each servant in the sample.

Once the results attained by the association between clinical instruments and the prevalence of epidemiological variables strengthened predictions, we deduct that clinical and epidemiological measures explain different dimensions of work leaves by MBD. This reinforces the importance of such association, both from a theoretical standpoint, through latency and dimensionality of the phenomenon (Czeresnia, 2008; Palinkas \& Hoiberg, 1982; Vinck et al., 2004), and from a practical or applied standpoint, through clinical and administrative implications (Carneiro, 2006; Faiman, 2012; Lacaz, 2016; Vinck et al., 2004).

Results strengthen the notion that the work of psychological evaluation needs to develop towards integrating epidemiological surveillance actions and clinical instruments with appropriate psychometric properties.
Thus, understanding the health-illness process resulting from work may achieve more defined contours (Lehman et al., 2017; Vinck et al., 2004; Wade \& Halligan, 2017), and provide stronger data for designing public policies, epidemiologically and clinically supported.

Hence, the role of the State Government is fundamental, since it makes important investments in occupational health. These include keeping updated databases, with demographic and occupational variables of the civil servants and epidemiological health indicators related to these same variables, as well as providing psychologist technicians from the examination service with appropriate instruction and clinical instrumentation. Such investments generate results that directly benefit the national treasure - since they qualify the expert evaluation (with more precision, less inconsistencies and mistakes), by reducing direct and indirect financial costs - and benefit, above all, the quality of life of thousands of civil servants and their families, with impacts on better public services for society.

Regarding the empirical results, we believe that the $39.3 \%$ of the unexplained variance of the outcomes may still be reduced by monitoring the cases that were predicted and did not result in benefits granted by MBD in the weeks that followed the assessment, since $60.7 \%$ of the outcome variance was explained transversally (at the time of answer). Possibly, such a result would be different if considered longitudinally, since the relationship mental suffering-benefit granting by MBD, or anxiety/depression--benefit granting by MBD may not be simultaneous.

\section{FINAL CONSIDERATIONS}

Although hypotheses had empirical support, this research showed some limitations: 1) prediction of benefit by MBD based on cross-sectional data. It is possible that the benefit is not concomitant with the disorder's beginning; thus, a study with a follow-up of the evaluated servants could overcome this limitation; 2) clinical inferences based exclusively on self-report instruments: we did not use other data sources for making implications on mental suffering, resilience, anxiety, and depression (direct observations, records, and reports by third parties); 3) possible outdated variables in the State of SC databases (education and civil status of servants), thus increasing the inaccuracy of the achieved results.

Despite these limitations, it seems possible to articulate psychology with epidemiology, as shown empirically. We intend neither to neglect differences, nor to ignore difficulties in the scope of the psychology-epidemiology dialogue. Such differences can be methodologically addressed, and a conversation between the two fields is possible, as some 
authors have already shown, theoretically and empirically (Czeresnia, 2008; Leviton, 1996; Machado et al., 2010; Mello et al., 2007; Palinkas \& Hoiberg, 1982; Vinck et al., 2004).

The epidemiological-clinical predictions for granting sick leaves explain more variance than those for determining other dependent variables, such as sick leave duration or SL repetition. The results presented here confirm that the association between epidemiology and psychology is viable and fruitful. Although they are distinct sciences, we empirically demonstrated that their remarkable contributions to health - which the scientific community has endorsed for decades - complement each other. Such articulation is rare in national and international literature, and enhances the psychological tradition of clinical studies.

Nevertheless, quantitative data have been strong arguments for changing reality, working conditions, and health, regarding managers. Successful public policies can make use of studies like this one, which articulates psychology with collective health in order to promote, prevent, and protect mental health in work environments.

\section{REFERENCES}

Alarcon, A. C. R. S. \& Guimarães, L. A. M. (2016). Prevalência de Transtornos Mentais em Trabalhadores de uma Universidade Pública do Estado do Mato Grosso do Sul, Brasil [Prevalence of Minor Mental Disorders among Employees of a Public University of the State of Mato Grosso Do Sul, Brazil]. Revista Sul Americana de Psicologia, 4(1), 46-68.

Almeida, M. B. F., Silveira, E. C. S. Trevisan, R. L., \& Cruz, R. M. (no prelo). Perícia Psicológica Administrativa da Saúde do Servidor Público [Administrative Psychological Evaluation of Public Servants' Health]. Revista Trabalho EnCena (Dossiê perícias em trabalho-saúde).

American Psychiatry Association. (2013). Diagnostic and Statistical Manual of Mental disorders - DSM-5 ( $5^{\mathrm{a}}$ Ed.). American Psychiatric Association.

Araújo, J. N. G., \& Barros, V. A. (2019). Work Psychology and the Work Clinics in Brazil. Laboreal, 15(2), 1-13. https://dx.doi. org/10.4000/laboreal.15515

Baasch, D., Trevisan, R. L., \& Cruz, R. M. (2017). Perfil Epidemiológico dos Servidores Públicos Catarinenses Afastados do Trabalho por Transtornos Mentais de 2010 a 2013 [Epidemiological Profile of Public Servants Absent from Work Due to Mental Disorders from 2010 to 2013]. Ciência \& Saúde Coletiva, 22(5), 1641-1650. https://dx.doi.org/10.1590/141381232017225.10562015

Bim, M. C. S., \& Murofuse, N. T. (2014). Benefício de Prestação Continuada e Perícia Médica Previdenciária: Limitações do Processo [Continued Benefit and Social Security Medical Evaluation: Limitations of the Process]. Serviço Social \& Sociedade, 118, 339-365. https://doi.org/10.1590/S010166282014000200007

Bjelland, I., Dahl, A. A., Haug, T. T., \& Neckelmann, D. (2002). The Validity of the Hospital Anxiety and Depression Scale. An updated Literature Review. Journal of Psychosomatic Research, 52(2), 69-77. https://doi.org/10.1016/S00223999(01)00296-3

Carneiro, S. A. M. (2006). Saúde do Trabalhador Público: Questão para a Gestão de Pessoas - A Experiência na Prefeitura de São Paulo [Public Worker Health: Question for People Management - The Experience in the City of São Paulo]. Revista do Serviço Público, 57(1), 23-49. https://doi.org/10.21874/rsp.v57i1.188

Carvalho, C. A. de, Pinho, J. R. O., \& Garcia, P. T. (2017). Epidemiologia: Conceitos e Aplicabilidade no Sistema Único de Saude [Epidemiology: Concepts and Applicability in Brazil's Unified Health System] ( $1^{\text {a }}$ Ed.). EDUFMA.

Codo, W. (1999). Individuo, Trabalho e Sofrimento: Uma Abordagem Interdisciplinar [Individual, Work and Suffering: An Interdisciplinary Approach] (4 $\left.4^{\mathrm{a}} \mathrm{Ed}\right)$. Vozes.

CFP Resolution No. 17 (2012). Dispõe sobre a Atuação do Psicólogo como Perito nos Diversos Contextos [Delimits Psychologists' Performance as an Expert in Different Contexts]. Conselho Federal de Psicologia.
Cruz, R. M. (2017). Perícia Psicológica no Contexto do Trabalho [Psychological Evaluation in the Work Context]. Vetor.

Cruz, R. M. (2020). Perícia Psicológica Trabalhista [Psychological Evaluation at Work]. Em C. S. Hutz, D. R. Bandeira, C. M. Trentini, S. 1. R. Rovinski, \& V. M. Lago (Orgs.). Avaliação Psicológica no Contexto Forense (pp. 265-681). Artmed.

Czeresnia, D. (2008). Epidemiologia, Ciências Humanas e Sociais e a Integração das Ciências [Epidemiology, Social and Human Sciences and Integration of Sciences]. Revista de Saúde Pública, 42(6), 1112-1117. http://doi.org/10.1590/S003489102008005000059

Decree $\mathrm{n}^{\mathrm{o}} 3.338,23$ june (2010). Aprova o Manual de Normas Técnicas Médico-Periciais [Approves the Medical-Official Technical Standards Manual] (2 ${ }^{\mathrm{a}}$ Ed.). Secretaria de Estado da Administração. DIOESC.

Faiman, C. J. S. (2012). Saúde do Trabalhador [Worker's Health]. Casa do Psicólogo.

Faro, A. (2015). Análise Fatorial Confirmatória e Normatização da Hospital Anxiety and Depression Scale (HADS) [Confirmatory Factor Analysis and Standardization of the Hospital Anxiety and Depression Scale (HADS)]. Psicologia: Teoria e Pesquisa, 31(3), 349-353. https://doi.org/10.1590/010237722015032072349353

Gomez, C. M., Vasconcellos, L. C. F. de, \& Machado, J. M. H. (2018). Saúde do Trabalhador: Aspectos Históricos, Avanços e Desafios no Sistema Único de Saúde [A Brief History of Worker's Health in Brazil's Unified Health System: Progress and Challenges]. Ciência \& Saúde Coletiva, 23(6), 1963-1970. https://doi.org/10.1590/1413-81232018236.04922018

Gonçalves, D. M., Stein, A. T., \& Kapczinski, F. (2008). Avaliação de Desempenho do Self-Reporting Questionnaire como Instrumento de Rastreamento Psiquiátrico: Um Estudo Comparativo com o Structured Clinical Interview for DSMIV-TR [Performance of the Self-Reporting Questionnaire as a Psychiatric Screening Questionnaire: A Comparativ Estudy with Structured Clinical Interview for DSM-IV-TR]. Cadernos de Saúde Pública, 24(2), 380-390. http://doi.org/10.1590/ S0102-311X2008000200017

Husain, N., Chaudhry, N., Rhouma, A., Sumra, A., Tomenson, B., \& Waheed, W. (2016). Validation of the Self-Reporting Questionnaire (SRQ 20) in British Pakistani and White European population in the United Kingdom. Journal of Affective Disorders, 189, 392-396. https://doi.org/10.1016/j. jad.2015.08.068

Lacaz, F. A. C. (2016). Continuam a Adoecer e Morrer os Trabalhadores: As Relações, Entraves e Desafios para o Campo Saúde do Trabalhador [Workers Keep on Becoming Ill and Dying: Relationships, Obstacles and Challenges for the Worker's Health Field]. Revista Brasileira de Saúde Ocupacional, 41(13), 1-11. https://doi.org/10.1590/23176369000120415 
Leão, A. L. M., Barbosa-Branco, A., Rassi Neto, E., Ribeiro, C. A. N., \& Turchi, M. D. (2015). Sickness Absence in a Municipal Public Service of Goiânia, Brazil. Revista Brasileira de Epidemiologia, 18(1), 262-277. https://doi.org/10.1590/19805497201500010020

Lehman, B. J., David, D. M., \& Gruber, J. A. (2017). Rethinking the Biopsychosocial Model of Health: Understanding Health as a Dynamic System. Social and Personality Psychology Compass, 11(8), e12328. https://doi.org/10.1111/spc3.12328

Leviton, L. C. (1996). Integrating Psychology and Public Health: Challenges and Opportunities. American Psychologist, 51(1), 42-51. http://doi.org/10.1037/0003-066X.51.1.42

Macêdo, E. de A., Simone, A., \& Lavras Costallat, L. T. (2017). Assessment of the Hospital Anxiety and Depression Scale (HADS) Performance for the Diagnosis of Anxiety in Patients with Systemic Lupus Erythematosus. Rheumatology International, 37, 1999-2004. https://doi.org/10.1007/s00296017-3819-x

Machado, J., Sorato, L., \& Codo, W. (2010). Saúde e Trabalho no Brasil: Uma revolução Silenciosa - O NTEP e a previdência Social [Health and Work in Brazil: A Silent Revolution - NTEP and Social Security] ( ${ }^{\mathrm{a}}$ Ed). Vozes.

Mari, J. J., \& Williams, P. (1986). A Validity Study of a Psychiatric Screening Questionnaire (SRQ-20) in Primary Care in the City of Sao Paulo. British Journal of Psychiatry, 148(1), 23-26. http://doi.org/10.1192/bjp.148.1.23

Ministério do Planejamento, Orçamento e Gestão (2010). Manual de Perícia Oficial em Saúde do Servidor Público Federal [Official Health Expertise Manual for Federal Public Servants]. Subsistema Integrado de Atenção à Saúde do Servidor.

Mykletun, A., Stordal, E., \& Dahl, A. A. (2001). Hospital Anxiety and Depression (HAD) Scale: Factor Structure, Item Analyses and Internal Consistency in a Large Population. British Journal of Psychiatry, 179(DEC.), 540-544. https://doi.org/10.1192/ bjp. 179.6 .540

Netsereab, T. B., Kifle, M. M., Tesfagiorgis, R. B., Habteab, S. G., Weldeabzgi, Y. K., \& Tesfamariam, O. Z. (2018). Validation of the WHO Self-Reporting Questionnaire-20 (SRQ-20) Item in Primary Health Care Settings in Eritrea. International Journal of Mental Health Systems, 12(1). https://doi.org/10.1186/ s13033-018-0242-y

Osmo, A., \& Schraiber, L. B. (2015). O Campo da Saúde Coletiva: Definições e Debates em sua Constituição [The Field of Collective Health: Definitions and Debates on Its Constitution]. Saúde e Sociedade, 24, 201-214. https://doi.org/10.1590/ S0104-12902015S01018

Palinkas, L. A., \& Hoiberg, A. (1982). An Epidemiology Primer: Bridging the Gap between Epidemiology and Psychology. Health Psychology, 1(3), 269-287. http://doi. org/10.1037/0278-6133.1.3.269

Paraventi, F., Cogo-Moreira, H., Paula, C. S., \& De Jesus Mari, J. (2015). Psychometric Properties of the Self-Reporting Questionnaire (SRQ-20): Measurement Invariance Across Women from Brazilian Community Settings. Comprehensive Psychiatry, 58, 213-220. https://doi.org/10.1016/j. comppsych.2014.11.020
Pasquali, L. (2017). Psicometria: Teoria dos Testes na Psicologia e na Educação [Psychometry: Test Theory in Psychology and Education]. Vozes.

Pesce, R. P., Assis, S. G., Avanci, J. Q., Santos, N. C., Malaquias, J. V., \& Carvalhaes, R. (2005). Adaptação Transcultural, Confiabilidade e Validade da Escala de Resiliência. Cadernos de Saúde Pública, 21(2), 436-448. https://doi.org/10.1590/ S0102-311X2005000200010

Santos, D. N. (2008). Review of the book Epidemiologia da Saúde Mental no Brasil [Epidemiology of Mental Health in Brazil], by M. F. Mello, A. A. F. Mello, \& R. Kohn (Eds.). Cadernos de Saúde Pública, 24(8), 1955-1956.

Sareen, J., Afifi, T. O., McMillan, K. A., \& Asmundson, G. J. G. (2011). Relationship Between Household Income and Mental Disorders. Archives of General Psychiatry, 68(4), 419. https:// doi.org/10.1001/archgenpsychiatry.2011.15

Secretaria de Estado da Administração de Santa Catarina (SEA) (2015). III Boletim Estatístico de Benefícios de Saúde do Servidor 2010-2013 [III Statistical Bulletin on Public Servants Health Benefits 2010-2013]. Cunha, J. C. B. \& Sefrin, S. R. G (Orgs.). DIOESC.

Secretaria de Estado da Administração de Santa Catarina (SEA) (2018a). IV Boletim Estatístico de Beneficios de Saúde do Servidor 2014-2016 [IV Statistical Bulletin on Public Servants Health Benefits 2014-2016]. Cunha, J.C.B., Trevisan, R.L. \& Sefrin, S. R. G (Orgs.). DIOESC.

Secretaria de Estado da Administração de Santa Catarina (SEA) (2018b). V Boletim Estatístico de Beneficios de Saúde do Servidor 2017 [V Statistical Bulletin on Public Servants Health Benefits 2017]. Cunha, J.C.B. \& Francisco, A.C. (Orgs.). DIOESC.

Silva, E. B. D. F., Tomé, L. A. D. O., Costa, T. D. J. G. Da, \& Santana, M. D. C. C. P. (2012). Transtornos Mentais e Comportamentais: Perfil dos Afastamentos de Servidores Públicos Estaduais em Alagoas, 2009 [Mental and Behavioral Disorders: Profile of Removals of State Public Servants in the State of Alagoas, Brazil, in 2009]. Epidemiologia e Serviços de Saúde, 21(3), 505-514. http://doi.org/10.5123/S1679-49742012000300016

Silva, M. P., Silva, R. M., \& Silva, J. K. B. (2014). Perícia Psicológica no Âmbito do Trabalho: Atuação numa Diretoria de Saúde do Servidor [Psychological Survey in the Workspace: The Work in a Public Health Board]. Psicologia Argumento, 32(79), 15-25. http://dx.doi.org/10.7213/psicol.argum.32.079.DS02

van Der Westhuizen, C., Brittain, K., Koen, N., Maré, K., Zar, H. J., \& Stein, D. J. (2018). Sensitivity and Specificity of the SRQ20 and the EPDS in Diagnosing Major Depression Ante- and Postnatally in a South African Birth Cohort Study. International Journal of Mental Health and Addiction, 16, 175-186. https:// doi.org/10.1007/s11469-017-9854-8

Vinck, J., Oldenburg, B., \& Lengerke, T. V. (2004). Editorial: Health Psychology and Public Health - Bridging the Gap. Journal of health psychology, 9(1), 5-12. http://doi. org/10.1177/1359105304036098

Wade, D. T., \& Halligan, P. W. (2017). The Biopsychosocial Model of Illness: a Model whose Time Has Come. Clinical Rehabilitation, 31(8), 995-1004. https://doi.org/10.1177/0269215517709890 